\title{
Persistência e mudança em sociedades de "folk" no Brasil ${ }^{1}$
}

\author{
Gioconda Mussolini (IN MEMORIAM)
}

No Brasil, e muito particularmente no Estado de São Paulo, "zona velha" e "zona nova" de povoamento são expressóes que correspondem não só a áreas geograficamente distintas, como também, pelo menos numa representação ideal, a dois tipos extremos em matéria de estabilidade social e de sedimentaçáo cultural. Quanto à primeira, encontramo-nos no domínio da integração cultural, da atividade rotinizada, de um ajustamento mais equilibrado do homem ao meio físico, onde ainda se pode procurar pela vigência de "folk ways", "folk lore" e "folk songs" em pleno funcionamento se se quiser caracterizar, pela sua posse, uma população campesina ou rústica ${ }^{2}$. Quanto à segunda, deparamos com aquele quadro típico que levou Pierre Monbeig a dizer que nas zonas pioneiras "em tôda a parte, na cidade como no campo, o viajante sente que nada é estável, nada é definitivo" (1952, p. 11). De um lado, portanto, a pouca mobilidade espacial e uma definição assentada da posição ecológica das várias cidades que exercem função de "centros de dominância" ou "capitais regionais". De outro, o verdadeiro nomadismo daqueles indivíduos que se habituaram a estar sempre no extremo de um trilho de estrada de ferro, na "boca do sertão", no ponto da última arrancada da "marcha para o oeste", muito embora tenham deixado atrás de si a situação próspera de outro centro ainda novo e promissor; zona de intensa competição entre as várias cidades pela disputa da posição de dominância sobre as áreas circundantes.
Um estudo da caracterização diferencial destas duas realidades poderia revelar, de início e num plano histórico, aspectos importantes presos ao nosso problema: na medida em que os estudiosos das sociedades de "folk", mesmo quando aparentemente indiferentes ao condicionamento histórico encaram este tipo de sociedade como vinculada a uma unidade maior de que é parte, o "background" diverso de duas zonas nos daria, no panorama mais amplo, o sentido de nossa "persistência" e de nossa "mudança”. Estamos pensando exatamente naquela ordem de problemas que Carl C. Taylor (1950, p. 419) levanta ao falar das áreas novas norteamericanas, elas próprias uma projeção das velhas e uma consequência de seu desenvolvimento:

Cada um dos tipos de comunidade que era estabelecido numa área de fronteira após outra, tinha uma sociedade nacional mais ampla atrás de si, um sistema de transportes e comunicação mais adequado e um corpo mais amplo de conhecimentos técnicos a seu dispor. As comunidades eram muitas vêzes compostas de elementos étnicos diferentes, sujeitos a novos ambientes físicos e engajados no processo de tocar para diante tipos de amanho da terra diferentes daqueles com que estavam acostumados. ... Muitas das comunidades rurais desde o início de sua existência praticaram uma agricultura comercializada em lugar de uma lavoura de subsistência. ... As comunidades rurais americanas, simples em sua primitiva história, tornaram-se complexas. 
Infelizmente, os antropólogos e sociólogos que no Brasil se vêm dedicando ao estudo de comunidades, não têm se interessado pela zona pioneira. A instabilidade desta, e que não é, evidentemente, o lado pelo qual nos interessaria, surtiu efeito negativo, impedindo que nos fôssem revelados os aspectos pelos quais realmente o seu estudo seria fecundo: as condiçóes de seu aparecimento, apanhadas em processo, condicionando suas possibilidades de ser ou se tornar mais ou menos "folk". Se algumas consideraçóes podem ser feitas neste sentido, as informaçóes vêm dos geógrafos ${ }^{3}$. A título de exemplo poderíamos apontar alguns aspectos em relação aos quais as zonas novas nos dáo o sentido de nosso "conservantismo" e de nossa "mudança”. Em primeiro lugar, como nas zonas velhas, sua expansão e florescimento continuam a prender-se a solicitações do mercado exterior. Se é possível condicionar a localização de nosso povoamento colonial ao tipo de nossa exploração econômica na época, voltada, antes do mais, para centros consumidores localizados fora do Brasil, igualmente não é possível explicar a "marcha para o oeste" por circunstâncias estritamente brasileiras ${ }^{4}$. Ademais, como outrora, as cidades da franja pioneira em geral não passam de um prolongamento da área rural; surgem em função dela, para serví-la, aspecto este que é bem patente nas funções que exercem ${ }^{5}$.

Por outro lado, porém, observam-se algumas diferenças significativas, das quais, a título de exemplo, apontaremos algumas. A velha cidade surgia do patrimônio que até o fim do século passado era uma instituição de caráter religioso: o fundador doava uma terra ao santo, fazia alí uma capela e, ao seu redor, se reuniam os homens para aproveitar da gratuidade dos terrenos ou, pelo menos, do baixo preço de seu arrendamento $^{6}$. Hoje, o nome se conservou, mas a instituição se laicizou: da tradição só resta a prática de levantar uma cruz na clareira em que se criará a cidade. Terminada a festa que acompanha o acontecimento e a benção da cruz, tudo decorre como num loteamento urbano qualquer. Diga-se, aliás, de passagem que também a experiência religiosa das "capitais regionais" da franja pioneira está a revelar uma verdadeira heterogeneidade de crenças e seitas e um ligeiro esmorecimento do catolicismo, fenômeno novo e inédito nas zonas velhas em seu nascedouro e nas quais o estudioso faz hoje do aparecimento de uma nova religião na comunidade, objeto de análise da quebra de homogeneidade cultural e sintoma de desorganização.

Poderíamos lembrar, além disso, que cada novo surto de expansão no Brasil, registrandose em momentos históricos diferentes, deu margem ao aparecimento de "tipos" característicos de ocupantes da terra e a uma variedade muito grande de relaçóes que se estabeleceram entre êles, em virtude das diferenças de propriedade quanto ao uso da terra, recursos econômicos e técnicos; e, em consequência, de diferentes tipos de cooperação e antagonismos a que estas relações deram origem ${ }^{7}$. Se, para citar apenas um exemplo, o fazendeiro ainda é figura de relêvo nas zonas novas, representa, contudo, o que se poderia chamar de "fazendeiro novo estilo" ${ }^{\text {. }}$.

Cremos ter dado uma idéia dos problemas que nos ocorrem e que só aparentemente podem parecer afastar-se do tema proposto. $\mathrm{O}$ próprio Redfield que, sem negar o valor da contribuição histórica na caracterização dos tipos societários que estabelece, atribui-lhe pequena importância quando pretende chegar ao aspecto que mais o interessa - a natureza da mudança social - revela, contudo, nas análises de fato realizadas em Yucatan, bastante sensibilidade ao condicionamento histórico quando tem que explicar resultados inexperados. E, admitindo que as sociedades possam ser mais ou menos "folk", ao definir a sociedade campesina aproxima-se de Foster para quem a sociedade 
de "folk" não é uma sociedade completa em si mesma e isolada, mas parte de uma unidade social maior (usualmente a nação) com a qual está estruturada vertical e horizontalmente ${ }^{9}$. Se, portanto, Redfield na sua polarização ideal insiste em considerar as sociedades de "folk" como isoladas e remotas em relação à influência urbana (no que é criticado por Foster), por outro lado, tomando a organização como critério básico do conceito de "folk", vê a possibilidade de, através do isolamento, certas sociedades que já passaram por intenso contacto, chegarem novamente a uma harmonia interna e uma eliminação de "incompatíveis" culturais ${ }^{10}$. Ademais, embora nem sempre distinga claramente "sociedade" de "cultura" de "folk" (porquanto, em seu estado de plena vigência, uma seria pre-condição da outra, como a cidade o é da civilização), não chega, contudo, a tornar os dois conceitos de tal modo inseparáveis a ponto de não acompanhar a persistência de elementos "folk" em sociedades "náo-folk" e vice-versa ${ }^{11}$.

No momento, portanto, em que se estabilizarem as áreas pioneiras, poderemos verificar até que ponto suas comunidades representarão semelhanças com a "aldeia campesina”, esta "casa em meio do caminho... entre as imaginadas polaridades", nas quais "persiste a ordem moral que prevalece nas sociedades primitivas, porém agora em relação persistente com uma ordem tecnológica e utensílios complicados, comércio, política e instituiçóes administrativas”. (Redfield, 1953, p. 224).

Quase que invariàvelmente, porém, os estudos de comunidade realizados no Brasil revelam, como dissemos, interêsse definido da parte de seus autores por áreas nas quais se espera verificar a qualidade de "organização cultural" e estabilidade social, selecionando-se, por esta razão, pontos que, além de situados nas "zonas velhas" de povoamento, sejam o suficiente isolados para que se anteveja a possibilidade de concretização daquela expectativa. A partir daí, então, tomando-se a introdução em cena de qualquer fator objetivamente considerado como meio de comunicação (a inauguração de uma estrada ou de uma linha de ônibus, a exploração de um produto solicitado pelo mercado externo, etc.), procura-se verificar como esta quebra de isolamento vai minando a situação anterior, pela difusão de elementos culturais que quebrem a homogeneidade interna. Implícita ou explicitamente, alguns dêstes estudos, pelo menos ${ }^{12}$, têm procurado testar no Brasil as conclusōes de Redfield e, desta forma, têm prescindido grandemente de uma investigação histórica rigorosa das comunidades estudadas, uma vez o autor acima pressupóe uma relação funcional entre os elementos característicos de uma situação (de folk ou civilização), relação esta que explicaria "a tendência ao seu aparecimento em conjunto e não como mero agregado fortuito, historicamente determinado"13.

Muitas das comunidades estudadas entre nós, porém, em lugar de terem passado de um primitivo estado de isolamento a um de contacto, são comunidades que, tendo por vezes outrora ocupado inclusive posição de dominância ecológica ou, pelo menos, estado na órbita de centros de significação econômica e social, sofreram depois um processo de retraimento em virtude da perda daquela posição. Por que então não fazer da situação passada objeto de verificação das conclusóes de Redfield? Se a quebra do isolamento tende a conduzir ao aparecimento de características que este autor associou ao contacto, a volta ao isolamento dever-se-á fazer acompanhar, igualmente, daquelas que se associam como variáveis dependentes. É claro que, como diz Foster, quando se analisa o conteúdo das chamadas culturas de "folk", fica-se surpreso ao verificar quão im- 
portantes são aqueles elementos que nelas se encontram justamente porque a sociedade não está isolada, mas em contacto, durante séculos, com a civilização ${ }^{14}$. Contudo, é importante verificar-se até que ponto o substrato mesmo da vida social (ponto que parece importante a Redfield) dá margem a um processo seletivo e readaptativo, tomando-se de empréstimo no presente (atual ou histórico) ou conservandose do passado aqueles elementos sócio-culturais que condigam com a situação vigente. Em outras palavras: nas comunidades sujeitas ao retraimento, a que nos referimos, ter-se-ia verificado o fenômeno do "empobrecimento cultural", observando-se, pela atuação de um processo seletivo, a retenção e reinterpretação daqueles elementos sócio-culturais anteriores, condizentes com a nova situação?

Embora não haja estudos focalizando pròpriamente esta questão, há elementos para se fazerem algumas consideraçôes ${ }^{15}$.

T. Lynn Smith (1947, ps. 159-178), analisando o que êle chama de "sistema agrícola" brasileiro, ressalta o papel das grandes "plantations" de cana de açucar, os engenhos, como crivo através do qual foram selecionadas as porçóes da herança européia que puderam penetrar na América Portuguesa e as que foram excluídas. E prossegue:

Não havia lugar, no Brasil rural, para a modesta granja do lavrador português, nem tão pouco para o sistema agrícola que êle recebera como herança... de seus antepassados e no qual, entretanto, ainda faltavam não poucos elementos importantes. As suas colheitas de produtos alimentícios que poderiam ter facilitado uma dieta muito mais equilibrada para a população brasileira, o arado de pau e, em geral, até o conhecimento rudimentar da roda e do animal de tiro, foram negados ao Brasil pela posição monopolizadora dos engenhos.
E Oliveira Viana também prende ao que êle denomina de "organização do clan rural", a "carência de institutos de solidariedade e cooperação" entre nós, principalmente de solidariedade e cooperação vicinais, tão comuns entre os portugueses:

Outras instituiçôes de cooperação social, vigentes ainda nas tradiçóes do povo luso, igualmente não se aclimatam aqui. É o caso das belas festividades aldeâs, das ceifas, das desfolhadas, das mondas, das vindimas, que na Península se fazem com o concurso dos vizinhos, entre bailados típicos, folguedos, tradiçôes, usanças rústicas... Nem a colheita do algodão ao norte e a apanha do café ao sul, nem o corte do arroz, nem a quebra do milho por tôda parte, criam iguais costumes de cooperação vicinal. Todos esses trabalhos são aqui penosos e tristes... (1952, I, p. 230). [...] Nas zonas agrícolas, onde se difunde o tipo do grande domínio independente... não se descobre nenhum traço ou associação entre vizinhos para fins de utilidade comum... O próprio costume dos "adjutórios" só é corrente entre a gente miseranda; não tem caráter geral: os lavradores médios e a alta classe rural não o praticam. (I. p. 231).

Que nos primeiros séculos o engenho tivesse representado o crivo de seleção e difusão de elementos culturais, substituindo as cidades brasileiras no papel de "centros secundários de influência urbana” (Redfield) em relação à Europa, não resta dúvida ${ }^{16}$. Contudo, uma análise mais profunda revela o porquê da seleção ao ver de Lynn Smith e Oliveira Viana, negativa. O tipo de análise a que se deverá proceder começará ainda mais longe. Assim, Roger Bastide, ao preocupar-se com o problema das vinculaçóes do folclore com o gênero de vida, estruturas sociais e mesmo, condiçôes geográficas dos meios a que este folclore se refere, estuda, em sugestivo artigo sobre o assunto (1951), 
as retençóes e reinterpretaçóes do folclore europeu no Brasil, procurando até nas condições climáticas brasileiras (maior uniformidade em relação ao clima europeu), na inversão de nossas estações do ano em relação à Europa, nas diferenças de gêneros de vida e distribuição demográfica, os motivos das alteraçôes das festas, presas lá a um calendário agrícola bem determinado, vigílias de inverno, etc. Analisa a perda de função de certos rituais europeus ou a sua mudança de função, a inversão de certos traços de uma para outra estação do ano, a modificação da hierarquia das festas, tudo isso contribuindo para o desaparecimento de certas tradiçóes ou para que o folclore adquirisse, entre nós, aquele "caráter fluido, cujas festas não são fixas, variando de localização no tempo de uma para outra região e, numa mesma região, muitas vezes de um século para outro" (p. 24). Desta forma, chega até a estabelecer uma "lei" de retenção: "Tudo o que altera o gênero de vida europeu, ocasiona o desaparecimento ou a transformação do folclore; tudo quanto recorda o gênero de vida europeu conduz à manutenção dos traços folclóricos” (p. 25). E o mesmo considera válido em relação ao folclore africano (cf. 1950). ${ }^{17}$

Ademais, apesar da importância do papel seletivo do engenho, órgão que era da Grande Lavoura, não se pode negar que ao lado desta uma outra seleção estava a se operar, prêsa à Agricultura de Subsistência ${ }^{18}$ e a tôdas as demais formas subsidiárias de exploração, e que depois forneceria os elementos básicos de nossa organização sociocultural rústica. Assim, por exemplo, se Antonil (1923, p. 73) fala em "lavradores obrigados ao engenho" ou no sistema de "ter cana obrigada à moenda" (p. 67), ressaltando a dependência dos arrendatários em relação aos senhores de terras, Oliveira Viana (1952, I, p. 191) aponta entre as razóes pelas quais nunca se criou entre as duas classes grande solidariedade, os processos rudimentares de beneficiamento. $\mathrm{O}$ arrendatário dispensa os engenhos da fazenda, na medida em que "o milho, o feijāo, o arroz, a cana, o café, ou são produtos imediatamente utilizáveis por êle, ou o são mediante operações rudimentares, com os 'molinetes', 'pilóes' e 'monjolos' primitivos."

Elemento desta economia subsidiária seria também a pequena pesca que se desenvolveria em todo o litoral brasileiro, legítima cópia dos aparelhamentos, técnicas e empregos portugueses, aos quais se mesclaram alguns elementos indígenas, e de cuja retenção nos poderiam dar idéia falsa os mapas de produção que, até o século passado, mal se referem a esta "pesca para o gasto", pondo em destaque apenas as "Armaçōes" ou seja, os estabelecimentos destinados à captura e indústria da baleia. Alcançando êste desenvolvimento apreciável da Bahia para o Sul, até o Estado de Santa Catarina, deixou registro apenas na toponímia litorânea, desaparecendo por volta de meados do século passado. No entanto, paralelamente, estava a sedimentar-se tôda a nossa organização de pesca, homogênea até mesmo em sua nomenclatura, de norte a sul do país ${ }^{19}$, e que só recentemente e apenas em alguns pontos do litoral, vai perdendo seu caráter "folk".

Ainda no mesmo sentido, apesar das condiçóes da escravidão tornarem impossível aos africanos introduzidos no Brasil perpetuarem certos traços de sua cultura material, de sua organização econômica, tipos de sua organização social e familial, refere-se René Ribeiro aos elementos $\mathrm{da}$ herança africana que persistiram, dispersos e reinterpretados" embora "como o mutirão, as sociedades de ajuda mútua, as irmandades do Rosário dos Pretos". (1952, p. 25). ${ }^{20}$

No campo da medicina de "folk", se bem que a contribuição africana e indígena sejam mais acentuadas em alguns pontos do país, como a Bahia e a regiāo amazônica, respectivamente, e, neste caso, dêm às práticas de cura um caráter mais místico e sacerdotal ${ }^{21}$ como 
pano de fundo mais geral, porém, destaca-se uma grande identidade quanto a estas práticas em relação aos modêlos portuguêses (até hoje vigentes em Portugal). Os "benzimentos" da zona rural são formas reconhecíveis e identificáveis dos "ensalmos" lusitanos, conservados não apenas em sua estrutura formal, mas mantendo quase que os mesmos significados e funções. Aqui, como lá, servem a comunidades que pouco burilaram o aspecto esotérico dos processos de cura, convertendo-os em setor pouco ritualizado da cultura, prestando-se, com facilidade, a se tornar um expediente vicinal em sua aplicação.

Falta-nos espaço para prolongar estas considerações. O que apresentamos é apenas uma exemplificação do processo de retenção seletiva de elementos culturais operada entre nós. $\mathrm{O}$ que restou do passado em muitas áreas, das quais foram subtraídos os fundamentos sociais organizatórios do início, foi justamente o que na lavoura se prendia a uma economia de subsistência, tanto nos métodos, como nos produtos selecionados; foi a pequena pesca de padrões organizatórios tìpicamente vicinais; foi o "mutirão", o "adjutório" e o "troca dia" da gente humilde, mutirão ao qual não falta o aspecto lúdico que Oliveira Viana lamenta não existir em nosso trabalho agrícola da Grande Lavoura ${ }^{22}$.

É claro que diferentes condiçóes ecológicas, diferentes fatôres históricos e as parcas comunicações existentes no Brasil, contribuíram para marcar de um cunho típico suas diversas áreas. Estudos recentes estáo se preocupando por uma focalização multi-dimensional destas diferenças em relação a alguns de seus aspectos ${ }^{23}$. É de esperar-se também que, paralelamente, se obtenha mais material sôbre as semelhanças, e elementos para explicar a grande uniformidade básica de alguns setores de nossa cultura de "folk".
Se deslocarmos, agora, a focalização um pouco mais para o lado propriamente organizatório ou seja, para as unidades sociais sobre as quais se apóiam as manifestaçôes culturais, o mesmo tipo de análise revela não só acomodaçôes sofridas pelas instituições alienígenas em nosso meio, como também as criações e sincretismos originais a que a nossa situação, também original, deu margem. Neste caso, o primeiro fator a considerar-se, quase que como uma variável independente, seria a nossa fraca densidade demográfica, fator pelo qual vários estudiosos de nossos problemas têm começado suas análises. Carlos Borges Schmidt (1951, p. 171), em seu trabalho sobre a vida rural brasileira, aponta para a dificuldade que existiu, até o século XVIII, de entre nós concentrar-se a população em aldeias, tal como se fazia em Portugal, fato que preocupava grandemente os governadores das províncias. E conclui que "a dispersão da população era um imperativo do ambiente natural e das técnicas agrícolas", sempre em busca de terras novas, de terras virgens. Roger Bastide também apela para o fato para explicar a decadência de muitos aspectos do folclore europeu no Brasil, principalmente quando exigiam cooperação e divisão de papéis. E T. Lynn Smith (1946) ao analisar nossos grupos de localidade, explica pela fraca densidade demográfica o fato de o grupo vicinal constituir a forma típica de nossas distribuiçóes espaciais, com dificuldade de passar para uma organização de maior amplitude, de base comunitária. À questão de como êste padrão distributivo espacial condicionou o isolamento e o contacto, voltaremos depois. No momento estamos interessados em verificar como as instituiçóes de que partilhamos desde o início e que pressupóem uma sociedade mais diferenciada, um todo mais amplo no qual se entrosam - Estado, Igreja Católica, etc. - ao se circunscreverem dentro de pequenos núcleos localmente "traduzidas" ou reinterpretadas. O 
problema é importante principalmente porque as vinculações dos grupos locais com a estrutura mais ampla de que fazem parte, ficam, muitas vezes, por assim dizer, em estado de latência e não raro o que chamamos de "mudança" não passa, em última análise, de um apêlo cada vez maior a recursos que a comunidade já continha como alternativas e aos quais passa apenas a recorrer com maior frequência.

Um primeiro aspecto a ser considerado é a existência de regras jurídicas efetivas, formalmente diversas do dispositivo e paralelas a êle, e que presidem, de fato, a organização jurídica da comunidade, por vezes entrando em choque com as leis vigentes no país ${ }^{24}$. Tal é o caso, por exemplo, do casamento religioso, dispensando o casamento civil (o único reconhecido por lei) e criando problemas sérios principalmente quando os indivíduos migram para as cidades onde o casamento civil é condição para uma série de garantias a que sua família tem direito. Mas há um outro aspecto sobre o qual queremos chamar particularmente a atenção: o da disposição da propriedade (móvel e imóvel) por uma série de convençôes locais que limitam, grandemente, a posse diferencial de bens. Tais práticas, evidentemente, encontram seu clima principalmente nas zonas velhas, onde tenha decaído o valor das terras. Então, embora a propriedade individual exista, os indivíduos possuam títulos dela e estejam cientes de seu valor, bens móveis e imóveis são postos à disposição de um maior número, inclusive sem remuneração alguma (tal como o caso das "terras de favor" no litoral paulista), por um sistema intensivo de empréstimos, o que significa que êstes bens não são retirados do processo de produção, mas cedidos aos que tenham trabalho disponível para empregá-los ${ }^{25}$.

Se passarmos ao campo religioso, observaremos também os reajustamentos a que foi submetido o Catolicismo ao se integrar em nossa sociedade colonial, bem como os con- trastes entre o catolicismo rural e o urbano no presente, contrastes estes que se explicam, em grande parte, pela ação das mesmas causas que atuaram para diferenciar nosso catolicismo em seu início e que ainda são vigentes em nosso meio rural.

Dado o caráter ritualístico da religião católica, prestou-se ela a uma "retenção" menos daqueles aspectos prêsos ao desenvolvimento de um contrôle íntimo e efetivo da ação, de que daqueles que se prendiam ao lado manifesto das comemoraçóes, dando margem ao convívio e ao divertimento. Ou, para empregar as palavras de Roger Bastide, "um catolicismo que era mais um clima de sentimento de que uma educação para a vida espiritual" (1951a, p. 336) e que, por isso mesmo, "deixou-se contaminar pelas superstiçôes dos índios e religióes dos africanos". Nem poderia ser de outra forma num país que, pela sua extensão e rarefação demográfica, teve que contar com capelães em vez de padres, capelães estes que, apesar das contínuas cartas pastorais contra a sua atuação, representavam os postos avançados da cristandade nos latifúndios esparsos ${ }^{26}$. E até hoje o nosso catolicismo rural é, tipicamente, um catolicismo de capelães e novenas.

Contra êste catolicismo "folk" levantouse, através da história, e continua a levantar-se ainda hoje, o catolicismo das ordens religiosas. Charles Wagley (1953) viu bem a perda que representa para a vida da comunidade por êle estudada o não aproveitamento, da parte da Igreja, de todo aquele potencial organizatório que se tinha criado em nome da fé em vários santos e, especialmente, ao redor de São Benedito, com suas irmandades de assistência mútua, etc. Contudo, êste fato é muito comum no meio rural: a luta da igreja contra um catolicismo "mais social que religioso, mais voltado para as coisas da terra, da terra brasileira, que para o sobrenatural", como diz Bastide. Visando purificar a religião das impurezas dos sincre- 
tismos, o clero entrou, não raro, em luta aberta contra o folclore católico, proibindo as danças de negros ante as portas das igrejas, as congadas e os maracatús, impedindo, desta forma, que se cumprissem os votos anualmente renovados aos santos, "pagando-se as promessas" de uma forma condizente com a maneira "folk" de dar expressão a seus sentimentos religiosos ${ }^{27}$. E assim, subtraindo uma forma de expressão sem, ao mesmo tempo, colocar em seu lugar outra realmente substitutiva (o que implicaria, é claro, num novo condicionamento cultural), contribuiu, com sua parcela, para este estado de apatia religiosa muitas vêzes apontado em nossas populaçóes rurais. Porque, como ressalta Redfield (1949, p. 371), “o povo deixa de crer em parte porque deixa de entender, e deixa de entender porque deixa de fazer as coisas que exprimem os sentimentos comuns".

Voltemos agora novamente à questão de nossa fraca densidade demográfica e do subsequente isolamento de nossos núcleos de população rural. Como, em abstrato, esta condição é altamente favorável ao conservantismo, ocorrem-nos algumas considerações a respeito, talvez suscitadas por observaçóes feitas nas chamadas "zonas decadentes", e que nos levam também a ponderar alguns aspectos relativos ao contacto e à mudança.

Tôda a comunidade que tenha chegado a um estado de grande isolamento desenvolve uma íntima dependência em relação ao ambiente: passa a contar consigo mesma e, neste sentido a integração pode ser considerada como significando o grau em que a cultura se adapta ao habitat. Os limites da área dentro da qual os membros de uma sociedade realizam a satisfação de suas necessidades, mesmo que se trate de maneiras "folk" e de uma população que viva numa base vicinal, nunca se circuns- crevem, porém, em relação a certos aspectos culturais, ao mundo imediato no qual garante a sua subsistência. O simples desenvolvimento de uma trama de relaçôes que transcendam os limites do grupo local imediato, por si mesmo náo implica em perda do carater folk pela sociedade e pela cultura. Pode-se, por este meio, estabelecer-se simplesmente uma participação mais intensa de vários núcleos vizinhos de povoamento na realização de tarefas comuns. E caberia aqui, para exemplificação, o folclore, em cujo campo se poderia especificar ainda mais esta forma de cooperação e de divisão de papéis com as Folias do Divino Espírito Santo, que sempre tiveram uma amplitude municipal.

Neste caso, quando se dá uma quebra desta trama de relações, levando os vários núcleos de população a se fecharem sôbre si mesmos, verifica-se a decadência de uma série de práticas coletivas, mesmo de natureza folk. A ilha dos Búzios por nós estudada (Cf. Emílio Willems e Gioconda Mussolini, 1952) é exemplo a propósito de desorganização cultural, por efeito negativo do isolamento como fator de persistência cultural. Por outro lado, o contacto dentro de uma área cultural uniforme (como, por exemplo, é o caso das populaçôes litorâneas do Brasil) pode representar, simplesmente, uma extensão, para cena mais ampla, das relações características - adaptativas e integrativas - do grupo imediato. Assim, para só citar um exemplo, o parentesco real ou ritual (compadrio) que se extende para além dos limites de um bairro, é uma das formas de ampliar o raio de segurança pessoal (que garante no grupo local), permitindo maior possibilidade de deslocamento espacial. Ao falar, portanto, em isolamento e contacto, deve-se ter em vista, também, o isolamento que estiola as tradições e o contacto que as torna possível.

Estas consideraçóes nos parecem importantes porquanto o êxodo e a flutuação de população são formas comuns de reação do nosso 
homem rural aos problemas criados por uma tecnologia atrazada e pelo "cansaço das terras". No caso do êxodo, as influências externas se fazem sentir de maneira indireta, uma vez que os indivíduos em aprêço não têm mais oportunidade de exercer papéis na comunidade. Neste caso, pareceria razoavel supor-se que a estrutura social, bem como as manifestaçóes culturais distribuidas aos ocupantes dos vários status, se mantivessem inalteradas desde que se conservassem na comunidade indivíduos que pudessem se distribuir por todos esses status e conhecedores de todos os papéis sociais. Contudo, é claro que o simples aspecto numérico tem importância e que uma comunidade tenha que reorientar suas relaçóes internas se a situação anterior implicava na colaboração de maior número nas atribuições coletivas. E êste é um caso muito comumente observado em nosso meio rural: o da influência externa levando à mudança não por aquisiçóes culturais ou organizatórias de fora, mas pela criação de problemas para os quais a comunidade local tenha que achar soluçôes.

No caso da simples flutuação da população, em que se verifica um deslocamento periódico de membros de uma comunidade, a importância da consideração dos tipos de contacto que se estabelecem, bem como dos lugares para onde se dá o deslocamento, aumenta, uma vez que os indivíduos voltam a exercer influência em seu meio. Neste caso, além das consideraçóes que já fizemos, gostaríamos de lembrar que mesmo quando os indivíduos passam a girar na órbita de grandes centros urbanos, suas relaçóes com estes podem ser de natureza periférica e, por aqueles mecanismos de "isolamento social" e "isolamento mental" de que fala Howard Becker, se verificaria uma adoção seletiva dos elementos culturais menos significativamente urbanos. Esta ordem de consideraçôes é tão óbvia que dispensa maiores comentários. Contudo, não é demais insistir em que um estudo de comunidade deve ser sempre complementado pelo dos demais centros com que mantenha relações (principalmente quando ocorre esta flutuação de população) a fim de verificar-se, quando for o caso, a natureza real dos contactos que seus membros mantém com o centro urbano, de "influência civilizadora" ${ }^{28}$ Ousaríamos dizer que a heterogeneidade das cidades representa, de certo modo, a possibilidade de se manter a homogeneidade rural. $\mathrm{E}$ isto para não voltar a falar nas características das cidades brasileiras, a maioria das quais não passando de um prolongamento da zona rural, muito longe de representar aquele tipo altamente secularizado que Redfield coloca como um dos extremos de seu continuum.

Finalizando: Se quiséssemos fazer um balanço dos elementos sócio-culturais que, apesar das diferenças regionais, permitem a conclusão da existência de grande uniformidade básica de nossos meios rústicos, colocaríamos, neste rol, a título de exemplo, a coivara, o mutirão, o "troca dia”, o adjutório, o "complexo cultural da farinha de mandioca", o "complexo cultural da pesca da tainha"; o compadrio, as novenas, as folias (principalmente as organizadas ao redor do Divino Espírito Santo e que parecem fornecer o paradigma para as demais).

Ao lado, porém, dêstes conteúdos culturais e dêstes padróes organizatórios mais óbvios, existem outros padróes que representam uma persistência formal, independentemente de conteúdos específicos. Para citar apenas um exemplo: a prática tão antiga de pagar "o têrço", empregada nos engenhos coloniais, em que o plantador entrava com a cana e o engenho the devolvia dois terços do produto. Este padrão, que ainda se preserva nos engenhos pequenos de muitos pontos do país, onde há o costume de "Dar a cana para moer à terça", extende-se 
também à prática de "dar o terço" ao dono da rêde no final da pescaria e pode ser depreendido mesmo na pesca em grande escala, como por exemplo, a praticada em Santos, na qual os brasileiros (os estrangeiros nem sempre) trabalham segundo um sistema de participação nos lucros e perdas que, mais complicado embora quanto ao número de partes em que se faz a divisão, revela o modêlo básico da partilha em "quinhões".

Contudo, levando a análise ainda mais longe, para buscar um nivel ainda mais abstrato de padronização, poderiamos atingir a explicação do porquê da persistência de certas atitudes em nossas populaçóes folk e que constantemente levam o pesquisador a "estranhar" certos comportamentos manifestos de sua parte. Infelizmente, êste campo ainda não tem merecido a atenção de nossos estudiosos. Neste particular, para também só citar um exemplo, ousaríamos dizer que o acolhimento que tem encontrado a medicina científica entre nossas populações rurais, não raro se prende a uma "configuração" do tipo a que estamos nos referindo e que contribui para dar uma característica mágica à estrutura mental destas populaçóes. A adoção relativamente pronta de medidas médicas, não implica, evidentemente, numa transformação correspondente de mentalidade: ao contrário, só na aparência há contradição. Porque, como tem insistido tantas vezes Roger Bastide, "o que domina na magia é o sincretismo", "a lei da magia é a da acumulação", de sorte que a própria medicina pode ser mais um de seus expedientes, incorporando-se aos mágicos e religiosos que já existem.

Infelizmente, pouco conhecemos dêstes padrôes a que Clyde Kluckhohn chama de "configuraçóes" da cultura e que poderiam explicar a resistência ou a receptividade de nossas populações rústicas a muitas inovações.

\section{Notas}

Este artigo foi apresentado originalmente no XXXI Congresso Internacional de Americanistas de São Paulo, em 1954, e publicado nos Anais do XXXI Congresso Internacional de Americanistas, São Paulo, Anhembi, vol. I, 1955, p. 333-353. Para sua republicação, neste volume, optou-se por manter a grafia original do texto, bem como, o sistema de referências bibliográficas usual na época de sua publicação original.

2 É claro que estamos falando de uma estabilidade relativa, pois que, enquanto a população aflui para as áreas pioneiras, a densidade demográfica em algumas regiốes de povoamento mais antigo tende a decrescer. Também, com exceção de alguns centros em que se verificou uma volta quase que completa a uma economia de subsistência, como por exemplo, na maior parte dos núcleos do litoral paulista, mesmo as áreas de povoamento antigo, decadentes, foram sacudidas muitas vêzes por uma sucessão de ciclos econômicos que lhes valeram uma nova revitalização. Tal é o caso, por exemplo, da plantação da laranja na Baixada Fluminense e que tirou o lugar do torpor em que tinha ficado com a decadência do café. Cf. Renato Silveira Mendes (1950).

3 Cf. Pierre Monbeig (1952); Nice Lecocq MüIler (1951) e Preston James (1951).

4 Comparem-se as seguintes passagens: "Na zona nova... a produção é limitada a alguns produtos destinados à exportação, submetidos diretamente às vicissitudes do mercado mundial." (Monbeig, 1952, p. 106) "Cultiva-se a cana, como se extrai o ouro, como mais tarde se plantará o algodão ou o café: simples oportunidade do momento, com vistas a um mercado exterior e longínquo, um comércio instável e precário sempre." (Caio Prado Júnior, 1945, p. 67, com referência ao Brasil colonial).

5 Tôdas as indústrias da área pioneira são ligadas à produção rural: "A agricultura é ainda o fundamento das funçóes comerciais e industriais. As instalaçôes industriais são mais numerosas nos 'bourgs' satélites, mas são sempre as 'maquinas de beneficiar' que aí são essenciais”. (Monbeig, 1952, p. 332).

6 José Arthur Rios (1951, p. 200) analisa o aparecimento das cidades brasileiras a partir dos 
latifúndios e considera que, tendo estes mantido sempre uma atitude profundamente antiurbana, era necessário que existisse um motivo muito forte para que se desse este fenômeno. E este motivo foi o religioso. "Este modo de fundar cidades apareceu, quando um fazendeiro ou grupo de fazendeiros, decidiu doar uma porção de suas terras a um santo, ao qual a nova cidade foi dedicada."

\section{Cf. Nice Lecocq MüIler (1951)}

Cf. Pierre Monbeig (1952, ps. 219-20) para uma visão de tôda a impersonalidade que está caracterizando as relaçóes humanas na zona pioneira, marcando sua ruptura com "o tempo dos fazendeiros". De fato, entre o sitiante e o gerente de um loteamento, o caracter das relaçóes já não pode ser o mesmo que mantinha o fazendeiro clássico, com sua clientela: "O paternalismo do 'patrão' em relação ao 'cliente' cede lugar às relaçóes de negócios entre o pequeno plantador, o comerciante e o industrial."

9 George M. Foster (1953). Redfield, situando o campesinato (peasantry) como um tipo particular dentro do "folk", embora o contraponha ao "puro folk" em virtude de sua vinculação com a cidade, diz: "Onde surgiram cidades, o povo do campo, dependente delas, desenvolveu relaçóes econômicas e políticas, bem como relaçôes de status com os habitantes da cidade, e assim se tornou este tipo especial de folk rural que chamamos de campesinato" com "tantos pontos de semelhança com a sociedade de folk, como com a vida urbana”. (1947, p. 306. O grifo é nosso).

10 Redfield (1934, ps. 57-69): “... cultura de 'folk' - êste modo de vida integrado e unificado, constituído tanto de elementos indígenas, como espanhóis e que caracteriza as aldeias do hinterland da península de Yucatan de hoje.” Tal como Foster o enuncia: "O tempo é uma parte essencial do conceito de cultura de folk: tempo para integrar os novos traços e complexos na estrutura de folk, para reelaborá-los e harmonizálos no conjunto funcional.” (1953, p. 164).

11 Redfield (1930, p. 2): “Os povos folk são rurais. Se o folclore é encontrado nas cidades, nunca o é em condição vigorosa, mas sempre decadente, sempre um vestígio."

12 Cf. Emílio Willems (1947); Donald Pierson (1951).
13 Redfield (1953a, p. 20): “...a frase 'ordem moral' indica a natureza dos laços entre os homens, mais que a categoria do conteúdo cultural.” Redfield (1953, p. 223): "O pessoal e o impessoal, o sagrado e o secular, os folk ways e as técnicas, a conduta culta e a das massas são conceitos antitéticos utilizáveis em proposições sôbre qualquer e sôbre tôdas as sociedades, independentemente do conteúdo particular do costume, da instituição, da religião e da estrutura social."

14 George Foster (1953, p. 164): "Se se examinarem as culturas que chamo de 'folk', crìticamente, numa base empírica, verificar-se-á que seus elementos mais significativos se filtraram do mundo intelectual de sua própria tradição de muitos séculos passados... As culturas de folk incorporam contìnuamente partes dos componentes mais intelectualizados de sua própria tradição ou das tradiçóes que foram assimiladas no passado ou são partes de uma supercultura da área”.

15 Uma fonte importante de material encontrase na obra editada por T. Lynn Smith e Alexander Marchant (1951), onde a maioria dos trabalhos focaliza, justamente, os vários problemas, de uma perspectiva histórica. Oliveira Viana (1952, 2 vols.), postas de lado algumas de suas apreciaçôes de caráter pouco científico, é fonte imprescindível para a compreensão do Brasil colonial numa multiplicidade de aspectos, principalmente relacionados com a nossa organização rural.

16 Cf. o excelente trabalho de José Arthur Rios (1951, ps. 188-208), onde analisa o papel marginal das cidades brasileiras até o século XIX, dependentes em relação ao meio rural, a importância do latifúndio e sua tendência anti-urbana, ligando-se diretamente ao meio exterior, cabendo-lhe, portanto, o papel de centro de inovações. Até o luxo arquitetônico é privilégio das fazendas. A cidade, em seu pleno sentido urbano, é realmente fenômeno do século XX.

17 Emílio Willems, através de seus trabalhos sobre os alemáes no sul do Brasil, tem mostrado a mesma ordem de ajustamentos e, até, o processo de desnivelamento cultural a que foram submetidos por dificuldade de conservar seu equipamento cultural, mesmo adaptativo, no novo meio . (Cf., por exemplo, Willems, 1951, ps. 209-225). 
18 Cf. Caio Prado Junior (1946). Apresenta a distinção entre "Grande Lavoura" e "Agricultura de Subsistência”, a primeira, ligada ao engenho, de fito exportador e voltada às instáveis solicitaçóes do mercado exterior; a segunda, suplementar àquela, função dela, constituindo como que a sua retaguarda econômica, e ocupando as áreas intersticiais dos grandes engenhos. tirão a qualquer dos grupos iniciais de nossa formação, porquanto é êle encontrado tanto na África, como entre os índios brasileiros e os portugueses, quanto aos outros aspectos apontados por René Ribeiro até hoje podemos observá-los nas organizaçóes de pretos. Comuns, por exemplo, são as sociedades de ajuda mútua dos participantes da Congada ou Moçambique. (Cf. Willems, 1947, sôbre o Moçambique).

21 Roger Bastide (1950) insiste no caráter místico da medicina do candomblé. "Não se deve confundir a medicina mística do candomblé com a chamada medicina popular" (p. 12). "A medicina do Candomblé... é sacerdotal... permanece religiosa”. (p. 28).

E em outro trabalho seu (1951, p. 30) mostra o cunho essencialmente religioso do catimbó do Ceará, cujos mestres se dirigem a Belém ou a Manaus, para alí fazer a aprendizagem sob a direção de pagés. Para uma visão da maneira pela qual atuam os pagés e do aspecto sincrético de suas práticas (mistura de elementos aborígenes e do moderno espiritismo) cf. Charles Wagley (1953, ps. 224-33).

Para se ter uma idéia da adoção, pelo imigrante alemão, de nossas práticas "folk" de cura, cf. Francisco S. G. Schaden (1946).

22 Possivelmente muitos estudiosos considerem o mutiráo de origem africana, pelo fato de muito comumente êle se fazer acompanhar do "jongo”. No litoral paulista, pelo menos, é comum esta associação. Por exemplo, há um tipo de mutirão realizado em tôda a Baixada da Ribeira e que se dá por ocasião da "bateção" do arroz. Os homens convocados para o trabalho espalham o arroz pelo chão e o separam da palha com movimentos circulares dos pés, sendo acompanhados pelo som do atabaque e de cantos. Um jongueiro, cuja única função é tocar viola e cantar no mutirão, puxa o canto; os homens de tôda a roda respondem com o estribilho. (cf. Nice Lecocq Müller, 1949, p. 27). Em todo o litoral norte do Estado de S. Paulo, o mutirão convocado para a "descida da canoa" também era acompanhado de "pontos" do jongo, prática que está desaparecendo. De qualquer maneira, porém, o mutirão é uma ocasião festiva e termina sempre em festa, tal como Jorge Dias (1953) descreve para Portugal.

23 Assim, por exemplo, Roger Bastide tem-se devotado, em vários trabalhos, não só às diferenças culturais dos grupos negros no Brasil, como também às diferentes situaçóes sociais que aqui encontraram e que, somadas à maior ou menor consistência interna de sua própria cultura permitiram maior ou menor conservantismo de suas práticas originárias. Ademais, tem procurado verificar a forma específica pela qual o negro tem se entrosado nas estruturas sociais dos vários pontos do país, secundando, assim o estudo do sincretismo cultural com a análise das condiçóes sociais especiais. Em seu excelente estudo sôbre a Macumba Paulista (1946, ps. 51-110) fornece ótimo material para a compreensão das diferenças dos cultos afro-brasileiros no norte e no sul do país.

24 Cf. o pequeno artigo, bastante sugestivo, de Cândido Procópio Ferreira de Camargo (1952, ps. 293-309).

25 A utilização comunitária do "tráfego de farinha", ou seja, do aparelhamento completo destinado à produção doméstica da farinha de mandioca, muitas vêzes sem retribuição alguma, aproximase da utilização dos moinhos de farinha de trigo em Portugal, sendo de notar-se que em alguns pontos do Brasil fala-se em "pagar a maquia", expressão correspondente à retribuição pelo uso dos moinhos em Portugal. (Cf. Jorge Dias, 1952).

26 Emílio Willems (1951, ps. 209-225) analisa a situação do imigrante no sul do Brasil, focalizando justamente a questáo do Estado e da Igreja, mostrando como a situaçáo aqui encontrada implicou em muitas mudanças na estrutura social das comunidades de imigrantes e revelando as soluçóes que encontraram para o caso, semelhantes em muitos sentidos às que estamos nos referindo. "A integração em unidades políticas e administrativas mais amplas náo era táo firme quanto nas socie- 
dades originárias. Na terra de origem, os colonos estavam acostumados à intervenção costumeira e ativa do Estado e da Igreja. Então, instituiçóes legais, educacionais e religiosas já tinham sido integradas na vida das aldeias camponesas. No sul do Brasil, com sua população espalhada e rarefeita, o contrôle do Estado estava longe de ser efetivo" (p. 212). E continua: "Muito mais difícil era a situação das paróquias católicas. Aqui, a falta de padres levou comumente a uma exacerbaçáo das funçóes do sacristão... Embora dependentes de padres, os paroquianos acostumaram-se a uma disciplina eclesiástica mais frouxa, e a atitude rebelde contra a autoridade de padres ordenados se tornou comum. Êste fato está em frisante contraste com a aceitação incondicional da autoridade eclesiástica nas comunidades camponesas do Velho Mundo" (p. 213).

27 Em Cunha (Estado de Sáo Paulo) tivemos oportunidade de verificar que a comunidade passou 4 anos sem realizar sua festa religiosa máxima - a festa do Divino Espírito Santo devido a interferências da igreja. Contudo, durante todo êste tempo, a estrutura da festa conservou-se em latência. Quatro anos após quando foi realizada, os membros da comunidade pagaram tôdas as promessas feitas, oferecendo cabeças de gado, jacás de milho, etc. prometidas anos antes. E foi uma festa riquíssima em pormenores folclóricos, conforme se pode ver na obra de Emílio Willems (1947) onde é analisada a mesma festa. $\mathrm{Na}$ Ilha de São Sebastião a congada desapareceu porque se impediu que os congueiros entrassem na igreja, vestidos a caráter, para retirar o andor de Sáo Benedito. Como não tinham outra forma de tratar com o santo e como, por outro lado, êle é tido como muito "justiceiro", não perdoando o náo cumprimento de promessas, tive oportunidade de verificar, nos anos que se seguiram ao desaparecimento da congada, o estado de espírito de seus participantes, temerosos de uma represália do santo. O rei do Congo, dada a sua posição de destaque, contou-me sonhos que tivera em que seu pai (o rei anterior) aparecia a reclamar com veemência, a realização da dança a S. Benedito. É interessante notar que mesmo as famílias brancas e melhor situadas na estrutura social, faziam promessas ao santo, o que implicava que seus filhos participassem da Congada. Colocadas na posição de festeiras nas comemoraçóes S. Benedito, foram as primeiras a reagir às limitaçóes impostas pela Igreja. Mas a verdade é que a festa desapareceu.

28 Os autores que se têm devotado principalmente aos estudos de cultos afro-brasileiros, fornecem material importante para uma série de consideraçôes sôbre o caráter pouco urbano das cidades do norte e nordeste do país. Ademais, revelam a cidade como centro em que se processa o sincretismo de religióes de naturezas várias. Em seu estudo sobre São Luís do Maranhão, Octavio da Costa Eduardo (1945, ps. 81-90) mostra a influência inversa do folk sobre o urbano: a pagelança guajajara, comum no interior do Estado, entrando na composiçáo de um novo quadro religioso total, em que se fundem elementos africanos, católicos e indígenas. As práticas xamanísticas dos índios Guajajara foram, segundo o autor, transmitidas em todos os seus detalhes para a capital do Estado, levadas por mestiços descendentes de índios e brancos ou índios e negros que migraram para a cidade. As mesmas observaçóes podem encontrar-se nos trabalhos de Roger Bastide e Renê Ribeiro.

\section{Referências Bibliográficas}

ANTONIL, André João. 1923. Cultura e Opulência do Brasil por suas Drogas e Minas. São Paulo.

BASTIDE, Roger. 1946. Estudos Afro-Brasileiros. $1^{a}$. Série. Contribuição ao Estudo do Sincretismo Católico-Fetichista. A Cadeira de Ogan e o Poste Central. A Macumba Paulista. Boletim LIX, Sociologia I, Fac. de Fil., Ciências e Letras da Un. de São Paulo.

BASTIDE, Roger. 1950. Medicina e Magia nos Candomblés. São Paulo.

BASTIDE, Roger. 1951. "O Folclore Brasileiro e a Geografia”, Boletim Paulista de Geografia, n., 8, ps. 19-34. São Paulo.

BASTIDE, Roger. 1951a. "Religion and Church in Brazil" in T. Lynn Smith e Alexander Marchant (eds.) $O p$. Cit., ps. 334-355.

CAMARGO, Candico Procópio Ferreira de. 1952. "Alguns Problemas Jurídicos em Xique-Xique", Sociologia, XIV, 4, ps. 293-309.

EDUARDO, Octávio da Costa. 1945. "Three-Way Religious Acculturation in a North Brazilian City", Afro America, Vol. II, n., 3, ps. 81-90. 
$300 \mid$ Gioconda Mussolini

FOSTER, George M. 1953. "What is Folk Culture?", American Anthropologist, Vol. 55, n. 2, Part 1, ps. 159173.

JAMES, Preston. 1951. "The Cultural Regions of Brazil" in T. Lynn Smith e Alexander Marchant (eds.), $O p$. Cit., ps. 86-103.

JORGE DIAS, Antonio. 1953. Rio de Onor. Comunitarismo AgroPastoril. Porto.

MENDES, Renato S. 1950. Paisagens Culturais da Baixada Fluminense. Boletim CX, Geografia 4, Fac. de Fil., Ciências e Letras da Un. de São Paulo.

MONBEIG, Pierre. 1952. Pionniers et Planteurs de São Paulo. Paris.

MÜLLER, Nice L. 1949. "Uma Vila do Litoral Paulista: Icapara”. Boletim Paulista de Geografia, n. 1, ps. 22-30. S. Paulo.

MÜLLER, Nice L. 1951. Sitios e Sitiantes no Estado de São Paulo. Boletim 132, Geografia 7, Faculd. de Fil., Ciências e Letras da Un. de S. Paulo.

MUSSOLINI, Gioconda. 1953. "Aspectos da Cultura e da Vida Social no Litoral Brasileiro", Revista de Antropologia, Vol. I, n. 2, ps. 81-97. São Paulo.

OLIVEIRA VIANA. 1952. Populaçôes Meridionais do Brasil. Rio de Janeiro. (10 volume).

PIERSON, Donald. 1951. Cruz das Almas. A Brazilian Village. Smithsonian Institution, Institute of Social Anthropology, Publication n. 12, Washington.

PRADO JR., Caio. 1945. Formação do Brasil Contemporâneo. Colônia. S. Paulo.

REDFIELD, Robert 1930. Tepoztlán, A Mexican Village. A Study of Folk Life. Chicago.

REDFIELD, Robert. 1934. "Culture Changes in Yucatan”, American Anthropologist, Vol. 36, ps. 57-69.

REDFIELD, Robert. 1947. "The Folk Society", The Amer. J. of Sociology, Vol. LII, no. 4, ps. 293-308.

REDFIELD, Robert. 1949. Civilização e Cultura de Folk (Trad. bras. de The Folk Culture of Yucatan, 1941), S. Paulo.
REDFIELD, Robert. 1953. "The Natural History of the Folk Society". Resumo publicado in Ciencias Sociales, n., 23, Vol. IV, ps. 222-228. Washington.

REDFIELD, Robert. 1953a. The Primitive World and Its Transformations. Nova York.

RIBEIRO, René. 1952. Os Cultos Afro-brasileiros do Recife. Um Estudo de Ajustamento Social. Boletim do Instituto Joaquim Nabuco, Recife.

RIOS, José Arthur. 1951. "The Cities of Brazil” in T. L. Smith e A. Marchant, Op. Cit., ps. 188-208.

SCHADEN, Francisco S. G. 1946. "Magia e Crenças Populares numa Comunidade Teuto-Brasileira”, Sociologia, Vol. VIII, n. 2, ps. 77-87.

SCHMIDT, Carlos Borges. 1951. "Rural Life in Brazil" in T. L. Smith e A. Marchant, Op. Cit., ps. 165-187.

SMITH, T. Lynn. 1946. Brazil: People and Institutions, Baton Rouge.

SMITH, T. Lynn. 1947. "Sistemas Agrícolas”, Rev. Bras. de Geog., Ano IX., n. 2, ps. 159-178.

SMITH, T. Lynn. e MARCHANT, A. (eds.) 1951. Brazil. Portrait of Half a Continent. Nova York.

TAYLOR, Carl C. 1950. "Techniques of Commnunity Study and Analysis as Applied to Modern Civilized Societies", in Linton, R. (ed.) The Science of Man in the World Crisis, N. York.

WAGLEY, CHARLES. 1953. Amazon Town. A Study of Man in the Tropics. Nova York.

WILLEMS, Emílio. 1947. Cunha. Tradição e Transição em uma Cultura Rural do Brasil. S. Paulo.

WILLEMS, Emílio. 1951. "Immigrants and their Assimilation in Brazil" in T. L. Smith e A. Marchant, $O p$. Cit., ps. 209-225.

WILLEMS, Emílio. e MUSSOLINI, Gioconda. 1952. Buzios Island: a Caiçara Community of Southern Brazil. Monographs of the American Ethnological Society, XX. Nova York.

\section{autora Gioconda Mussolini}

Professora da Cadeira de Antropologia/USP

Mestre em Ciências (Sociologia)/Escola Livre de Sociologia e Política

Recebido em 13/11/2009

Aceito para publicação em 13/11/2009 